\title{
A escolarização como projeto de civilização ${ }^{*}$
}

\author{
Cynthia Greive Veiga
}

Universidade Federal de Minas Gerais, Faculdade de Educação

O título da sessão para a qual este trabalho foi escrito, "A escola como dispositivo, como prática", sugere evidentemente uma abordagem baseado no autor que produziu o sentido e a função metodológica do termo dispositivo. Gostaria de retomar as proposições de Michel Foucault, na intenção de avaliarmos essa apropriação especificamente no campo da história da educação, isso porque o autor elabora esse conceito de forma que possibilite outra forma de pensar-se os objetos e conceitos da História.

Foucault delimitou a função metodológica do termo dispositivo para demarcar uma diferença no entendimento do objeto sexualidade, em História da sexualidade. Ele quis produzir um deslocamento da compreensão deste objeto, não como tematizam os biólogos, os historiadores das idéias ou mesmo os historiadores das práticas sexuais, mas dando visibilidade a um "dispositivo de sexualidade" (Foucault,

* Trabalho apresentado na sessão especial realizada na $25^{\mathrm{a}}$ Reunião Anual da ANPEd, (Caxambu, MG, 29 de setembro a 2 de outubro de 2002).
1981, p. 244). Isso implica a seguinte função metodológica do termo:

$\left.1^{\circ}\right)$ Demarcar uma rede que pode estabelecer-se entre elementos heterogêneos, ditos e não ditos, tais como: discursos, instituições, organizações arquitetônicas, regulamentações, medidas administrativas, enunciados científicos, proposições filosóficas, morais, filantrópicas.

$2^{\circ}$ ) A natureza da relação entre tais elementos, discursivos ou não, está inscrita em um jogo de poder, ou seja, de mudanças de posição e de modificação de funções, ligado a configurações de saber que dele nascem e o condicionam.

$3^{\circ}$ ) Além de ser uma estrutura de elementos heterogêneos, um dispositivo é de natureza essencialmente estratégica, um tipo de formação que em determinado momento histórico teve como função principal responder a uma urgência, e que supõe certa manipulação das relações de força, certa intervenção racional e organizada nestas relações de força. Foucault sintetiza: 'É isto, o dispositivo: estratégias de relações de força sustentando tipos de saber e sendo sustentado por elas" (idem, p. 246). 
Ao mencionarmos a maneira como a educação escolar foi produzida historicamente, estaríamos nos referindo à "escola como dispositivo" ou a um "dispositivo de escolarização"?

Se quisermos nos aproximar das proposições de Foucault, vamos observar que "escola como dispositivo" e "dispositivo de escolarização" são duas coisas distintas, na medida em que a escola, para Foucault, é um dos elementos que compõem a rede que ele denomina dispositivo, da mesma forma que a prisão não é o dispositivo, mas o aprisionamento; ou o sexo não é o dispositivo, mas a sexualidade, nem a clínica é o dispositivo, mas a loucura, bem como não é a doença o dispositivo, mas a medicalização.

Queremos dizer com isso que podemos problematizar a educação escolar na História não apenas como já foi tematizada com base nas idéias sobre a pedagogia, ou ainda apenas baseados em ênfases nas práticas escolares, mas também ressignificar o objeto escola valendo-se de um "dispositivo de escolarização". O que seria isso? Ao apresentarmos a orientação metodológica foucaultiana, reafirmamos que a escola não é o dispositivo, mas a escolarização, uma rede heterogênea de elementos que lhe dá visibilidade e ocultamento, nas formas discursivas e não-discursivas. É uma estratégia inscrita em jogos de poder, ligada a configurações de saber que deles nascem e também os condicionam; enfim, a escolarização como estratégia de poder. Precisaríamos então rever as nomenclaturas. Sendo a escola o objeto, na abrangência que propõe Foucault, temos que as denominações "história da educação" ou "história da escola" não dão conta da dimensão metodológica que Foucault propõe. Talvez precisássemos falar de uma história da escolarização, de forma que apreendêssemos não a "escola como dispositivo", mas o "dispositivo de escolarização".

Entre outras coisas, isso nos permitiria, mediante algumas analogias com os objetos do autor, pensar as relações que a partir de determinado contexto histórico se estabeleceram, por exemplo, entre analfabetismo/ignorância e escola. Foucault afirma que é o hospício que produz o louco como doente men- tal; poderíamos dizer o mesmo em relação ao dispositivo de escolarização, ou seja, é a escola que produz o analfabeto como ignorante. Este exemplo talvez deixe mais clara a inversão que pretendemos fazer ao estabelecermos a escolarização como o dispositivo: uma rede que se estabelece diante de elementos heterogêneos que envolvem os discursos, o espaço escolar, as idéias, o currículo, os materiais escolares, os procedimentos administrativos etc.; a natureza das relações entre esses elementos está no âmbito das relações de poder e é de caráter estratégico, confirmando-as como produtos e produtoras de saber.

Outro tema importante a ser destacado são as proposições de Foucault relativas à produção de uma tecnologia de controle que ele afirma estar presente em diferentes instituições, tais como o hospital, o exército, a escola, a prisão, a fábrica. Esta tecnologia recebe o nome de poder disciplinar (Foucault, 1981, p. 105). Embora o autor tenha desenvolvido de forma muito sintética as técnicas de controle em relação à escola, sabemos que muitos autores também o fizeram; dessa maneira, gostaríamos de discutir as apropriações com base em algumas questões.

Tomando o dispositivo escolarização, podemos afirmar que as relações que configuram os elementos em rede, como estratégias de poder, são da mesma natureza da doença, da loucura, da sexualidade, do aprisionamento?

Foucault afirma que os hospitais não se redefiniram baseados em uma técnica médica, mas diante da introdução de técnicas de controle - a disciplinarização do espaço hospitalar -, possibilitando a produção de novas práticas e saberes médicos. Isso foi em razão principalmente ao fato de que, no sistema epistemológico da medicina no século XVIII, com base no modelo classificatório de Lineu, as intervenções não ocorreram propriamente na doença, mas no meio: ar, água, temperatura, alimentação etc. É uma medicina do meio que está se constituindo, na medida em que a doença é concebida como fenômeno natural, obedecendo a leis naturais (idem, p. 107).

Em relação à escola, ele afirma: 
Nas escolas do século XVIII os alunos também estavam aglomerados e o professor chamava um deles por alguns minutos, ensinava-lhe algo, mandava-o de volta, chamava outro etc... Um ensino coletivo dado simultaneamente a todos os alunos implica uma distribuição espacial. A disciplina é, antes de tudo, a análise do espaço. É a individualização pelo espaço, a inserção dos corpos em um espaço individualizado, classificatório, combinatório. (Foucault, 1981, p. 106)

Na perspectiva foucaultiana, saber e poder estão intimamente relacionados, na medida em que o exercício do poder é lugar de formação do saber, e também que todo saber constitui relações de poder. Dessa forma, o hospital não é apenas o lugar de cura, mas também o instrumento de produção, acúmulo e transmissão de saber; por analogia, a escola está na origem da pedagogia; a prisão, da criminologia; o hospício, da psiquiatria.

Não há dúvida que o desenvolvimento do que se costuma chamar de uma pedagogia científica teve como origem as preocupações relativas a como tornar o ensino mais racional e eficaz. Também estas questões, em um primeiro momento, remetem à organização da classe, como é o caso do ensino mútuo e suas técnicas de controle e disciplina, para posteriormente se desenvolverem pedagogias renovadoras na relação com o conhecimento, baseadas, principalmente, no desenvolvimento da biologia, da medicina e da psicologia.

A pergunta que se coloca aqui é se essa perspectiva metodológica condiz com nossa compreensão dos processos de escolarização da sociedade. Diria que em parte: a contribuição dos pressupostos foucaultianos é realmente significativa para a compreensão da história da escolarização, mas, a partir do momento que deslocamos nossas análises para as condições de possibilidades da escolarização, outras questões se colocam. Queremos afirmar com isso que as condições de possibilidade do aprisionamento, por exemplo, podem não ser as mesmas das da escolarização.

Façamos antes uma ressalva. Em suas diferentes obras, Foucault apresenta, antes de mais nada, estra- tégias metodológicas - não para destacar os sujeitos, mas para compreender a formação dos saberes (ciência), as instituições e as estratégias de poder. Suas obras estão situadas historicamente no debate com os marxistas franceses e sua crítica principal está na percepção de que não existe sinonímia entre poder e Estado, ou ainda, não é se desfazendo do Estado que estaremos nos desfazendo das redes de poder. Ele observa que essa problemática teve origem na formação de tais redes, em que estiveram presentes duas formas de análise: "uma que remetia ao sujeito constituinte, e outra que remetia ao econômico - em última instância, à ideologia e ao jogo das superestruturas e infraestruturas" (idem, p. 6). Sua proposição de análise é fazer um deslocamento do sujeito constituinte para uma trama histórica que dê conta da constituição do sujeito nesta mesma trama. Assim, afirma: "É isto que eu chamaria de genealogia, isto é, uma forma de história que dê conta da constituição dos saberes, dos discursos, dos domínios do objeto etc..., sem ter que se referir a um sujeito, seja ele transcendente com relação ao campo de acontecimentos, seja perseguindo sua identidade vazia ao longo da história" (idem, p. 7).

A grande contribuição de Foucault está exatamente na perspectiva metodológica de que não se pode tomar a categoria sujeito como algo dado a priori, que tem uma inserção social ou que está excluído da sociedade, ou mesmo buscá-la no par dominante/dominado; ele demonstra que a configuração dos indivíduos na sociedade é de uma natureza muito mais complexa. Dessa maneira, reafirmando, o objeto de Foucault não é o doente ou o louco, mas as estratégias que permitiram sua produção como tal.

Neste aspecto, as apropriações metodológicas de Foucault para a história da escolarização são fundamentais, como é possível perceber em já abundante bibliografia. Tem sido possível, com base em suas contribuições, romper com as análises de compreensão da escolarização que tomam a idéia de sujeito com posições preestabelecidas - se pertencem ao grupo dos dominados ou dos dominantes, ou ainda com a idéia de remeter-se ao Estado, como uma fonte única 
de poder que arbitrariamente se impõe para escola, alunos e professores.

Retomemos a questão: as condições de possibilidades do aprisionamento são da mesma natureza da escolarização? A mesma trama histórica que dá conta de situar a constituição do sujeito como louco, doente, ou criminoso, dá conta de situar a constituição do sujeito como escolarizado ou não? E ainda, a produção do doente, do criminoso ou do analfabeto como um problema estabeleceu-se na mesma proporção, no mesmo contexto e para os mesmos grupos sociais?

É preciso observar que estamos lidando com questões muito diferentes. Por exemplo, no caso da doença, temos uma situação inerente à natureza humana - o de deparar-se com a situação da morte, e que atinge a todos -, mesmo que a produção do doente tenha sido bastante diferenciada ao longo da história. Se, nos tempos feudais, os corpos dos doentes poderiam refletir a podridão de sua alma (Duby, 1998), a partir de fins do século XVIII a produção do doente vai referir-se à relação com o meio físico e, posteriormente, também a relação com o ambiente cultural.

A questão do analfabetismo como problema, mesmo de acordo com a abordagem de Foucault, é uma produção da escola, mas há aí alguns diferenciais que precisam ser analisados. Para isso, busco outro referencial teórico, baseado nas proposições de Norbert Elias.

Elias e Foucault são autores que recorrem a procedimentos metodológicos distintos, mesmo porque se colocam questões diferenciadas de análise, mas possuem algumas aproximações, seja na contribuição que trazem para a historiografia, seja na maneira de aproximarem-se do objeto.

Chartier (1990) observa que

Entre Elias e Foucault são grandes as diferenças que se prendem fundamentalmente com a oposição entre o pensamento da duração, onde as formas sociais e psicológicas deslizam de uma para outra numa continuidade longa - o que Elias designa pelo termo figuracional changes -, e um pensamento de descontinuidade, que considera essenciais as rupturas entre as diferentes formas sociais ou discursi- vas. Todavia, ambos fazem apelo a uma revolução na história, ao obrigar esta disciplina a pensar de outra forma os seus objetos e seus conceitos. (p. 79)

Na apresentação à obra de Elias (1993), ${ }^{1}$ Renato Janine Ribeiro faz o seguinte comentário:

Norbert Elias adota, assim, como idéia chave, a tese de que a condição humana é uma lenta e prolongada constituição do próprio homem. [...] Desta convicção de princípios, Elias retira conseqüências metodológicas importantes - torna-se imprescindível, para um estudo sério do homem, articular toda sorte de documentos e toda espécie de ciências.

Bem antes de Foucault, ele entende, como o autor d'A Arqueologia do saber, que todo e qualquer texto ou mesmo gesto de um pensador merece, por princípio, a atenção de quem o estuda, e da mesma forma os dos não pensadores.

Uma rede enorme de elementos significantes assim se constitui, com a diferença de que para Michel Foucault o essencial se dará numa relativa sincronia (as epistemes de que ele tratou em A Palavra e as coisas), e para Elias numa decidida diacronia - num trajeto que se estira ao longo dos séculos, cobrindo pelo menos todo o segundo milênio da era cristã, e que destila um sentido, o da civilização entendida como processo, como verbo que se substantiva, o civilizar dos costumes. (p. 9-10)

Dessa maneira, as questões que esses autores se colocaram são fundamentais na diferenciação dos seus percursos metodológicos.

Roberto Machado, na introdução de Microfísica do poder, ${ }^{2}$ afirma que a inovação de Foucault, em 1961, pela História da loucura, estaria em estudar os sabe-

${ }^{1}$ A obra de Elias foi escrita na década de 1930; a primeira edição em alemão é de 1939, na Suíça. Somente em 1969 foi reeditada na, então, Alemanha Oriental. A primeira tradução francesa é de 1973-1975, e a primeira tradução inglesa é de 1978 (Garrigou \& Lacroix, 2001).

${ }^{2}$ Foucault (1981), edição organizada por Roberto Machado. As datas das obras de Foucault indicadas no texto referem-se às publicações na França. 
res sobre a loucura para estabelecer o momento e as condições de possibilidade do nascimento da psiquiatria. Posteriormente, outras obras suas - Vigiar e punir (1975) e o primeiro volume de História da sexиalidade (1976) - amadurecem as questões trazidas em As palavras e as coisas (1966) e A arqueologia do saber (1969), ou seja, a introdução nas análises históricas da "questão do poder como um instrumento de análise capaz de explicar a produção dos saberes".

Elias, ao produzir $O$ processo civilizador, colocava a seguinte questão: "como os homens se tornaram educados e começaram a tratar-se com boas maneiras?" (Elias, 1994a, p. 3). No prefácio do volume 1, em 1936, afirmava:

Este livro tem como tema fundamental os tipos de comportamentos considerados típicos do homem civilizado ocidental. É muito simples o problema que coloca. O homem ocidental nem sempre se comportou da maneira que estamos acostumados a considerar como típica ou como sinal característico do homem civilizado. (Elias, 1994a, p. 13)

Na introdução à edição alemã de 1968, a questão apresenta-se da seguinte maneira:

[...] como e por que, no curso de transformações gerais da sociedade, que ocorrem em longos períodos de tempo e em determinada direção - e para as quais foi adotado o termo desenvolvimento - a afetividade do comportamento e experiência humanos, o controle de emoções individuais por limitações externas e internas, e, neste sentido, a estrutura de todas as formas de expressão, são alteradas em uma direção particular? $?^{3}$ (idem, p. 214)

${ }^{3}$ A ênfase no termo desenvolvimento dá-se a fim de demarcar a diferença com o termo progresso. Isso se refere principalmente às recorrências a Nietzsche. Este autor, em Para a genealogia da moral, editada em 1887, afirmava: "Desenvolvimento de uma coisa, de um uso, de um órgão, nessa medida, pode ser tudo, menos seu progressus em direção a um alvo, e menos ainda um progressus lógico e curtíssimo... é pelo contrário, a sucessão de processos mais ou menos independentes um do outro... A forma é fluída, mais o sentido é mais ainda" (Nietzsche, 1974, p.316).
Para desenvolver suas questões, Elias utiliza-se de alguns termos básicos, tais como configuração, interdependência e equilíbrio das tensões. ${ }^{4} \mathrm{O}$ termo configuração, o mais importante e abrangente em sua obra, é utilizado para traduzir uma formação social com base na relação de interdependência entre os indivíduos. Dessa maneira, cada ação individual depende de uma série de outras, que por sua vez modificam a própria figura do grupo social, tanto na dimensão macro quanto na micro. A reprodução das configurações supõe um equilíbrio flutuante de tensões; portanto, o seu rompimento produz necessariamente uma nova configuração, que supõe outro equilíbrio de forças. Sua intenção é captar as diferentes configurações sociais. E é dessa maneira que Elias interpreta aquilo que ele denominou de processo de civilização, como uma dinâmica que pressupõe alterações nas relações de poder e controle dos indivíduos, alterando as relações de interdependência e possibilitando a consolidação dos controles estatais.

Segundo Elias, esta dinâmica não pressupõe nem uma evolução, na perspectiva darwinista de progresso automático, nem uma mudança, palavra que para ele possui um conteúdo inespecífico e não é suficiente para explicar os fatos. Sua perspectiva está na concepção da dinâmica das relações presentes entre os indivíduos e a sociedade, não como dois objetos distintos que se inter-relacionam, mas na percepção da existência de uma inerradicável interdependência das funções individuais, na qual cada pessoa singular está em dependência funcional de outras. Afirma o autor:

Assim, cada pessoa singular está realmente presa; está presa por viver em permanente dependência funcional de

Para Nietzsche, diferente de desenvolvimento, "A grandeza de um progresso mede-se até mesmo pela massa de tudo aquilo que deve ser sacrificado a ele; a humanidade como massa sacrificada à prosperidade de uma única espécie mais forte de ser humano isso seria um progresso...” (Nietzsche, 1974, p. 316).

${ }^{4}$ Para explicitação desses termos, foram utilizadas basicamente Introdução à sociologia (Elias, 1980), a introdução à edição alemã de 1968 (Elias, 1994a) e as reflexões de Chartier (1990). 
outras; ela é um elo nas cadeias que ligam outras pessoas, assim como todas as demais, direta ou indiretamente, são elos nas cadeias que a prendem. Essas cadeias não são visíveis e tangíveis como grilhões de ferro. São mais elásticas, mais variáveis, mais mutáveis, porém não menos reais, e decerto não menos fortes. E é essa rede de funções que as pessoas desempenham umas em relação as outras, a ela e nada mais, que chamamos sociedade. (Elias, 1994b, p. 23)

Estas concepções lhe possibilitaram desenvolver uma interpretação da dinâmica das civilizações totalmente original. Elias demonstra que a estrutura do comportamento civilizado está inter-relacionado com a organização da sociedade sob a forma de Estado, ou seja, as mudanças nos sentimentos de vergonha e delicadeza mudaram os padrões do que a sociedade exige e proíbe. As condições de possibilidade para a consolidação do Estado, por meio da monopolização da força física, estiveram em estreita relação com a alteração nos processos de autocontrole dos indivíduos, com base nas relações de interdependência presentes na dinâmica de formação dos diferentes grupos sociais e dos processos de reagrupamentos sociais.

Dessa maneira, ele discute as formas diferenciadas das alterações dos comportamentos sociais aceitáveis e a materialização das estruturas mentais e emocionais em códigos e regras de comportamento, mediante estágios diferenciados. ${ }^{5}$

Em um primeiro momento, Elias explora o conceito de cortesia na Idade Média, originário dos cortesãos que gravitavam em torno dos senhores feudais; portanto, uma atitude de comportamento que se referia a um lugar social em distinção às pessoas rudes e camponesas. Segundo ele, não foi característica das regras cortesãs uma grande restrição às emoções; isso somente vai ocorrer a partir do século XVI, por causa dos novos reagrupamentos sociais, propiciados pelo afrouxamento da hierarquia social medieval, pela for-

5 Elias compara a produção dessas dinâmicas na França, Alemanha e Inglaterra. Para este texto, valemo-nos fundamentalmente, do modelo francês. mação de uma nova aristocracia e pela conseqüente elaboração de outras distinções sociais. Aqui ganha materialidade o conceito de civilidades, no contexto histórico de crescente individualização e monopolização da força física pelo Estado. A extinção da nobreza guerreira baseada no cavaleiro e no senhor feudal, a formação de uma nova aristocracia de monarcas absolutos, aliadas ao desenvolvimento das classes burguesas, fez com que o conceito de civilidade se elevasse à categoria de comportamento social aceitável - civilidade entendida como controle de emoções e formação disciplinada como um todo.

Um autor francês, em 1675, citado por Elias, assim expressava as mudanças de seu tempo: "as palavras cortês e cortesia começam a envelhecer e não constituem mais bom uso. Dizemos hoje civil, honneste; civilité, honnesteté" (Elias, 1994a, p. 112).

É curioso observar que, neste momento, como forma de marcar uma distinção social, a aristocracia passa a associar cortesia a um modo burguês de comportar-se, para desqualificar este grupo. Civilidade e decência haviam substituído cortesia e afabilidade, e querem indicar outras formas de regulação dos impulsos e emoções, como sinais de distinção da "boa sociedade". Neste aspecto, Elias salienta: “... a questão de bom comportamento uniforme torna-se cada vez mais candente, especialmente porque a estrutura alterada da nova classe alta expõe cada indivíduo de seus membros, em uma extensão sem precedentes, às pressões dos demais e do controle social” (idem, p. 91).

A monopolização da força física pelo Estado, no momento em que deixa de ser permitido o livre uso da força física entre as pessoas, fez desencadear todo um movimento de contenção dos impulsos emocionais, sendo que o controle mais complexo e estável das condutas passa a ser mais instilado nos indivíduos, na busca da produção de uma "segunda natureza” (Elias, 1993, p. 197).

Entretanto, no decorrer das tensões e acontecimentos do século XVIII, o conceito de civilidade passou a ser insuficiente para traduzir uma consciência do modo de ser e estar na sociedade. Segundo Elias, a primeira evidência literária disso está na obra de 
Mirabeau, em 1760, na qual o autor expressa sua crítica social à tradição da corte, na perspectiva reformista de transformá-la. A questão que se apresenta para Mirabeau é o fato de que os comportamentos, atitudes e hábitos em vigor não passavam de uma farsa, o que o autor denominou "falsa civilização", pois a "civilização nada faz pela sociedade se não lhe dá por igual a forma e a substância de virtude" (Elias, 1994a, p. 54). O homem civilizado era nada mais do que uma versão ampliada do gentil-homem, uma maneira de expressar a auto-imagem das classes altas, ou ainda de diferenciá-las em relação à outras. Do homem civilizado Mirabeau quer derivar uma característica geral da sociedade: uma civilização. Mas isso não se referia a uma dimensão revolucionária, e sim a um movimento de evolução que deveria transformar os governantes e os governados, como parte do programa dos fisiocratas e dos reformistas franceses. Civilização, para Mirabeau, é entendida como uma moralidade possuidora de leis cíclicas que os governantes precisavam conhecer e usar, pois os processos auto-reguladores deveriam ser compreendidos e orientados por uma burocracia sadia e esclarecida (idem, p. 61).

Segundo Elias, em Holbach (Sistema social, editado em 1774) a palavra civilização aparece com freqüência:

A razão humana não é ainda suficientemente exercitada: a civilização dos povos não se completou ainda; obstáculos inumeráveis se opuseram até agora ao progresso do conhecimento útil, cujo avanço só poderá contribuir para o aperfeiçoamento de nosso governo, nossas leis, nossa educação, nossas instituições e nossa moral. (Holbach apud Elias, 1994a, p. 61)

Dessa maneira, um novo elemento manifesto interpõe-se nesse contexto: é necessário tornar toda uma sociedade civilizada. Alguns setores das elites se dão conta de que a civilização não é apenas um estado, mas um processo que deve prosseguir. Assim, civilização passa a referir-se a um padrão universal de moral e costumes. Ainda segundo Elias (1994a):
O processo de civilização do Estado, a Constituição, a educação e, por conseguinte, os segmentos mais numerosos da população, a eliminação de tudo o que era ainda bárbaro ou irracional nas condições vigentes, fossem as penalidades legais, as restrições de classe à burguesia ou as barreiras que impediam o desenvolvimento do comércio este processo civilizador devia seguir-se ao refinamento de maneiras e à pacificação interno do país pelos reis. (p. 62)

Transformar uma nação turbulenta em um povo pacífico, perigoso apenas para seus inimigos - esse é o ideal a ser perseguido pelos monarcas. Tal concepção de civilização é tomada como um programa de reforma que iria culminar, no século XIX, na autoimagem dos países europeus em relação a outras sociedades, que lhes cabia civilizar. Com as mudanças políticas do século XIX, Elias observa que a libertação do poder externo, ou ainda a diluição das hierarquias nobiliárias, além do processo de novos reagrupamentos sociais, produziu um novo movimento na medida em que, terminadas as formas absolutistas de poder, é o autocontrole que se absolutiza - as injunções e proibições sociais tornam-se cada vez mais parte do indivíduo por meio de um superego regulado.

Para Elias, a idéia de modernização da sociedade, a partir da organização dos estados modernos, não passa pela infra-estrutura econômica, mas por um processo de racionalização que afeta as mentalidades e o dispositivo social.

As alterações dos processos de autocontrole dos indivíduos estiveram relacionados aos processos de mudanças nas configurações sociais (nobreza cortesã, aristocracia absolutista, burguesia) e nas relações de interdependência dos indivíduos, como forma de produção de diferenciação e visibilidade social. Este movimento esteve associado principalmente à monopolização da força física pelo Estado, engendrando outras relações de poder entre os indivíduos e alterando suas relações de interdependência, ao ocorrer uma mudança de equilíbrio entre coerções externas e internas e, portanto, alterações nos modos de controle. Nesse sentido, o objetivo de Elias não é descrever uma transformação puramente cultural ou mental das 
configurações sociais, mas demonstrar sua hipótese de interação entre as transformações das estruturas de poder estatal e das estruturas mentais; dessa forma, o autor reintroduz a política e reabilita o indivíduo, articulando-o ao movimento da história.

Com base nos elementos metodológicos aqui destacados, voltamos à questão indicada anteriormente, qual seja: as condições de possibilidade de escolarização da sociedade são as mesmas do aprisionamento ou da medicalização? Afirmávamos que apenas em termos; isso porque é possível pensar que tais condições de possibilidade não se referem nem necessariamente a técnicas de controle, nem propriamente a um saber pedagógico, mas particularmente à monopolização dos saberes elementares pelo Estado. Quero dizer com isso que as condições de escolarização da sociedade não teriam sido possíveis sem esse procedimento. A associação dos saberes pedagógicos produzidos a partir do século XVI às técnicas de controle social, em direção à produção do dispositivo escolarização, somente se tornaram possíveis quando o Estado monopolizou tais técnicas e saberes, no momento em que se tornou definitivamente necessário para o programa civilizador a incorporação dos pobres na sociedade civilizada.

Como vimos, entre os séculos XVI e XVIII observa-se um lento processo de transformação dos comportamentos e hábitos, de auto-regulação e de controle das emoções. As discussões a respeito da oferta da escolaridade para toda a população somente foram possíveis no momento em que, de um lado, as classes altas e médias já se percebiam francamente civilizadas, e de outro, quando perceberam que isso lhes permitia enfrentar a questão posta por Holbach, ou seja, que "a civilização dos povos ainda não se completara". Os não-escolarizados colocam-se como problema para a efetivação de um programa de civilização de maneira muito diferente daquele dos lou$\cos$, doentes ou criminosos, e de forma ainda mais particular, porque se refere a um setor da população com especificidades cada vez mais visíveis - a população infantil pobre -, síntese da esperança da produção de nações pacíficas e ordeiras.
O que se quer chamar a atenção aqui não é para as técnicas de controle produzidas para a educação da infância, mas para o acolhimento da infância pela política, pelo Estado, basicamente com um peso maior do daquele conferido por Foucault em relação aos outros dispositivos que ele analisa.

É curioso observar que dos grandes temas da história, sejam eles as guerras, os personagens, ou mesmo os ciclos econômicos, a luta de classes, a dinâmica das práticas sociais etc., o tema da educação tenha se configurado como um capítulo à parte e, em geral, tratado como consequiência de determinados acontecimentos políticos e econômicos.

Penso ser importante determo-nos um pouco mais sobre a questão da monopolização do saber pelo Estado, no século XIX, e a importância desse procedimento para a consolidação da civilização como forma das populações européias referirem a si mesmas.

As análises que Elias fez dos processos de monopolização da força física e dos processos de tributação para a consolidação dos Estados nacionais podem trazer-nos indicadores metodológicos para afirmarmos que também a monopolização dos saberes elementares pelo Estado, a partir do século XIX, foram fundamentais para a estruturação das formas de governos constitucionais.

Os processos de homogeneização cultural e de habitus possibilitados pela escolarização obrigatória não teriam sido fundamentais para completar o processo civilizatório, mediante a produção de novas formas de socialização? A especificidade do dispositivo escolarização em relação a outros objetos de Foucault, não se deu exatamente por possuir a priori uma dinâmica de inclusão social, orientada pela burocracia e pela administração estatal, diferentemente de outros procedimentos como, por exemplo, o da doença e o da loucura?

Em um primeiro momento, estamos compreendendo que a análise da escolarização situa-se na continuidade do processo de civilização e que este dispositivo é fundamental para aprofundar a teoria da civilização, na perspectiva de sociedade que se autointerpreta como tal. A monopolização do saber pelo 
Estado e a universalização da instrução ampliou para toda a população os modelos de autocoerção, o domínio das emoções, os sensos de vergonha e pudor, disseminando outra configuração de sociedade ao inventar a educação escolarizada como categoria da atividade social.

Esse é o diferencial em relação ao que ocorreu entre os séculos XVI e XVIII, em que podemos falar da produção de uma pedagogia, mas não da escolarização.

As preocupações em relação à educação dos filhos estiveram bastante presentes entre a burguesia togada, desde o século XVI, principalmente por meio da formação jurídica. Este foi o novo modelo cultural para ascensão na corte, no momento ainda em que a retórica se separa da dialética. A promoção da retórica pelos jesuítas fortaleceu o lugar das humanidades literárias nos colégios e configurou-se como o modelo de excelência cultural das elites, contribuindo para a valorização do sucesso individual pela reputação e pelo talento. Dessa forma, a corte, no século XVIII, estabeleceu-se como lugar de competição generalizada e de integração entre as elites. Foi no contexto da competição de talentos e do ideal de distinção intelectual que as monarquias mantiveram a recusa em estender os saberes a outros grupos sociais; para isso seria necessária uma reforma, senão a transformação das relações de poder.

A nova pedagogia da ratio studiorum não foi a única que circulou nesse contexto, mas também aquelas que apontaram para um novo tratamento da infância de uma maneira geral. Refiro-me aqui particularmente aos manuais de civilidade, tanto aos tratados de civilidades do aprendiz cortesão quanto àqueles que se transformaram em tratados de civilidade pueril e cristã dos lassalistas, destinados a crianças pobres. Há de problematizar-se até que ponto a monopolização da força física pelo Estado, combinada com os processos de individualização e formas de autocoerção, não interferiram na produção da pedagogia desse tempo. A discussão sobre os castigos físicos é um exemplo, o que podemos observar nas propostas, dentre outros, de Gusmão, Fénelon e Locke (Ferreira, 1988).
Alexandre de Gusmão, em obra de 1685, A arte de criar bem os filhos na idade da puerícia, mesmo condenando os mimos, defendendo a disciplina e obediência, indicava castigos físicos moderados. François Fénelon (1651-1715), em Da educação das filhas, indicava que se deveria "ameaçar pouco, castigar ainda menos e aplicar penas tão ligeiras quanto possível, mas sempre acompanhadas de circunstâncias que pudessem provocar na criança a vergonha e os remorsos" (Ferreira, 1988, p. 273). John Locke, em Alguns pensamentos sobre educação, de 1708, também desconfiava dos castigos; seu ideal de autodisciplina passava pela necessidade de inspirar na criança o desejo de boa reputação e o horror à infâmia (idem, p. 278).

Elias demonstrou em seu texto que uma das características do processo civilizador esteve relacionado à economia das pulsões, cuja moderação se faz por meio do desenvolvimento dos sentimentos de vergonha, repugnância e embaraço. Assim, afirma: "O conflito expressado no par vergonha-medo não é apenas um choque do indivíduo com a opinião social prevalecente: seu próprio comportamento colocou-o em conflito com a parte de si mesmo que representa essa opinião" (Elias, 1993, p. 242). O sentimento de vergonha reproduz-se na pessoa por força do hábito, na medida em que as restrições externas foram sendo transformadas, pela estrutura das sociedades, em autorestrições e quanto mais abrangente e diferenciado tornou-se o círculo de auto-restrições no qual se manifesta a conduta da pessoa (idem, p. 243).

A escolarização no século XIX, pela extensão do autocontrole ao conjunto das relações sociais, é também uma extensão do controle da violência (castigos físicos) sobre as crianças, interferindo no âmbito privado das famílias em geral. O modelo de civilização produzido previa a reprodução das formas de comportamento presentes no interior de uma configuração social aristocrático-burguesa, para toda a população, de forma que transformasse as coerções externas em coerções interiorizadas.

No contexto do século XIX, por meio da monopolização dos saberes elementares pelo Estado, observa-se, portanto, a produção de um dispositivo de 
inclusão de todos na civilização; neste sentido, a identidade de escolarizado/não-escolarizado produziu novas relações de interdependência entre os grupos sociais, indicando outra configuração social. Como na monopolização da força física, a monopolização dos saberes pelo Estado diluiu as relações de saber na sociedade, particularmente entre as populações pobres, fazendo desencadear todo um movimento de contenção dos seus saberes e, com isso, tornando possível a delegação da educação dos seus filhos ao Estado.

É evidente que a universalização da instrução elementar e a extensão social das formas de comportamento civilizado constituíram um aprofundamento do controle das normas de conduta, e isto esteve relacionado à produção de novas formas de sociabilidade e de distinção social, engendradas pela escolarização.

Podemos afirmar, portanto, que a difusão da escolarização como categoria de atividade social foi fundamental para os processos de alteração da sociabilidade em curso, ao longo do século XIX e no início do século XX, bem como para as mudanças dos mecanismos de produção das distinções sociais que significaram alterações expressivas nas relações de gênero, geração, etnia e classe social.

Segundo Elias, o conceito de civilização expressa a consciência que o Ocidente tem de si mesmo e descreve aquilo que constitui o seu diferencial: "o nível de sua tecnologia, a natureza de suas maneiras, o desenvolvimento de sua cultura científica ou visão de mundo" (1993, p. 23). Esta maneira de referir a si mesmos dos povos ditos civilizados foi, sem dúvida nenhuma, uma realização da escolarização. A monopolização dos saberes pelo Estado deu conta de realizar a difícil tarefa enfrentada pelas elites políticas e intelectuais ao longo do século XIX, ou seja, a de estender a todos as técnicas das civilidades, sem contudo desfazerem-se das práticas de diferenciações que tanto marcaram a sociedade da corte. A questão era como se desfazer da pedagogização, presente do século XVI ao século XVIII, por meio da escolarização.

A universalização do acesso aos saberes e a escolarização em massa marcou o grande diferencial em relação a outros tempos históricos, pela dimensão inclusiva de todos, ou, mais especificamente, dos pobres, nos processos de socialização em curso na sociedade. Como se produziu esse diferencial?

Apesar de diferentes autores tratarem dos processos de escolarização presentes na sociedade desde o século XVI, é possível que os acontecimentos dos séculos XVI ao XVIII estejam mais relacionados a formas de pedagogização que propriamente a escolarização, porque se produzem como componente da aprendizagem de civilidades. Essas formas de pedagogização se referiram a preocupações relativas ao exercício de uma nova conduta na aprendizagem, que desse conta da transmissão dos comportamentos socialmente aceitos e em produção na sociedade daquele tempo. É com base nessa dinâmica que encontraremos uma pedagogização das relações sociais, na tentativa de tornar as ações e os sujeitos previsíveis. A invenção da escola nesse tempo foi dotada dos instrumentos necessários para a pedagogização das relações sociais, instrumentos estes que estiveram em consonância com os processos de produção das novas configurações sociais: tempo, espaço, manuais, métodos, disciplinas escolares. Entretanto, tais instrumentos fizeram-se nas limitações que a estrutura social da época também indicavam, e tão bem percebidos pelas elites do século XVIII. Nos séculos XVI e XVII, na maneira como se fez a crítica das práticas cortesãs, e mesmo das civilidades, como artificialismo, indicaram-se os limites da pedagogização das relações sociais em três sentidos: na perspectiva de uma falsa "pedagogização", porque limitada às regras e às normas de obediência e controle que vêm do exterior, mas também na perspectiva de sua restrição a um grupo social, e ainda no fato das formas escolares estarem autonomizadas de outras relações sociais. A grande revolução do século XIX foi exatamente a substituição da pedagogização das relações sociais pela escolarização; mais que tornar gestos e ações previsíveis, foi preciso indicar o caminho da produção da previsibilidade, não mais para um grupo restrito, cuja aprendizagem parecia estar concluída, mas para toda a sociedade. 
Portanto, a realização plena da civilização pressupôs ser civilizado como razão universal, mas, mais que isso, como uma manifestação interior de cada um e não como algo imposto do exterior. As experiências das pedagogizações anteriores eram insuficientes para tal, bem como as experiências escolares específicas de um grupo restrito da sociedade.

A diferenciação entre os períodos anteriores e o século XIX deu-se nessa inversão, buscando-se a predominância, não das formas escolares da retórica e da "falsa civilidade" nos processos de socialização, mas das configurações sociais nos processos de escolarização como caminho para produção da previsibilidade. Tais formações sociais referem-se às relações de gênero, geração, etnia e classe sociais, na maneira como estavam sendo constituídas na sociedade.

Portanto, a perspectiva do Estado de incluir os pobres na escolarização para completar o processo civilizatório pressupôs a homogeneização das relações sociais que, ao mesmo tempo, somente se estabeleceram como homogênicas por pressuporem uma diferenciação. Concretamente, nesse sentido a escola estrutura-se como prática social com base no dispositivo escolarização; é produtora e reprodutora de formas sociais, da socialização, expressa na difusão da cultura escrita, do saber científico, e na produção dos talentos e da individualização.

Isso implicou a perspectiva de homogeneizar nas escolas as relações de gênero, para o estabelecimento de uma cultura masculina no tratamento das relações individuais e sociais, na definição dos papéis sexuais e na consolidação de uma sexualidade contida na dinâmica destes papéis e no núcleo familiar. Também se socializaram na escola as categorias que se referem à geração, primeiro a infância e depois a adolescência, produzindo-se os modelos de criança inteligente, bemcomportada, e de jovem responsável, como formas civilizadas de vivência dessas categorias.

Ainda se socializou na escola uma perspectiva branqueada de cultura: as referências de civilidade estiveram de acordo com o predomínio dos valores de uma etnia, de uma raça. Mas também a escolarização disseminou uma cultura de classe, ao difundir as regras de ser bem-sucedido na sociedade, por meio da competitividade dos talentos e da meritocracia.

Dessa forma, temos que o processo de monopolização do saber pelo Estado abriu caminho para os processos de inclusão diferenciada dos indivíduos na sociedade. E este é o tema fundamental que nos permite compreender as técnicas de controle dos corpos e das mentes dos diferentes indivíduos, e a maneira como organizam-se e produzem-se os micropoderes. Tal qual no pressuposto da civilização, também para as elites a escolarização está concluída, é tarefa terminada como forma de referir a si mesmo e estabelecer-se no mundo.

Possivelmente seja este o ponto sobre o qual precisaríamos refletir melhor. A dinâmica da escolarização foi uma dinâmica de inclusão social, uma vez que para as elites este fator seria fundamental para completar-se o processo de civilização. As relações de poderes que se estabeleceram com base nessa dinâmica, e que possibilitaram a produção de uma nova pedagogia, já não se referem mais a uma "falsa pedagogização", cujas ações se exercem do exterior para o interior do indivíduo, mas a processos de educação que devem se manifestar no interior do indivíduo, na descoberta de talentos, manifestações de potencialidades; enfim, que devem possibilitar a produção das condições de previsibilidade.

A monopolização dos saberes pelo Estado e a sua efetiva consolidação, no final do século XIX, criou condições para a produção de saberes que ultrapassaram a "falsa pedagogização", revelada nas práticas de adestramento e castigos físicos, de memorização e de dor, por uma pedagogia que fizesse da civilização a própria natureza humana, homogeneizada para toda a sociedade.

Como bem nos indicou Foucault, antes de mais nada essas mudanças engendraram técnicas de poder que realizaram um controle detalhado e minucioso do corpo: gestos, atitudes, comportamentos, hábitos, discursos. Para Elias, são ainda técnicas de controle das emoções, pelas quais, com base em determinado contexto histórico, a manifestação de determinadas emoções foi considerada inoportuna, sinônimo de periculosidade e perturbação. 
Como esses referenciais podem contribuir para a compreensão da história da escolarização no Brasil?

É preciso destacar, inicialmente, a impossibilidade de referir-se à nação brasileira como uma civilização, mesmo porque é impossível transportar um conceito que teve uma construção histórica tão demarcada. Nas nações européias do século XIX concluiu-se a "consciência da civilização, a consciência de superioridade de seu comportamento e sua corporificação na ciência, tecnologia ou arte" (Elias, 1994a, p. 64). Portanto, constituiu-se como componente dessa imagem uma referência ao outro, nãocivilizado, que deveria ser civilizado.

Entretanto, isso não significou, evidentemente, que no Brasil o termo não tenha sido incorporado pela sociedade, ou mesmo pelo Estado. As elites políticas e intelectuais brasileiras, em geral, ao apropriaremse do termo civilização, ao longo do século XIX, não o tomaram para se referir a uma nação, mas como forma de produzir a sua auto-imagem. Na tradição intelectual brasileira do século XIX e início do século XX, a representação de um Brasil não se fez com base no conceito de uma nação civilizada que se autoreconhece como tal, mas constituiu-se pela permanente dúvida em relação às condições de possibilidade de tornarem seus habitantes civilizados.

Outra questão importante refere-se ao processo de formação do Estado brasileiro. A monopolização da força física e a organização da "sociedade da corte" não se fizeram com base em uma herança de relações feudais, cujas alterações das configurações sociais tiveram origem na aristocracia. A sociedade brasileira do século XIX estruturou-se baseada em laços de interdependência entre os membros da aristocracia e das elites econômicas, o que possibilitou inclusive o rompimento com a metrópole; ou seja, um acordo entre aristocracia e proprietários de escravos. No entanto, a presença de relações escravistas na organização do Estado brasileiro possibilitou a produção de uma cultura de poder público indistinta da do privado, favorecendo o desencadeamento de redes de clientelismo, cujos laços de interdependência eram muito fortes.
Diferentemente de outras nações, no Brasil a monopolização dos saberes elementares deu-se juntamente ao processo da monopolização da força física pelo Estado. Nesse aspecto, a ênfase da escolarização não se fez na busca de completar um processo de civilização já em curso, mas de estabelecer as civilidades e, principalmente, legitimar e dar visibilidade a uma nova configuração de poder em construção. Isso se manifesta principalmente na produção de cargos públicos e de uma rede de funcionalismo, inserindo novas relações de poder na rotina das populações.

Finalizando, temos que, apesar das guerras, da devastação ambiental e das tecnologias da destruição, o que ainda rege a maioria das populações ocidentais, no século XXI, são os mesmos princípios discursivos da civilização, da maneira como foi constituída e consolidada no século XIX: a superioridade e supremacia de uma razão universal. Quando trazemos para o debate os problemas da escola, expressos pela vivência de seus sujeitos, precisamos refletir sobre a natureza destes problemas. Para alguns setores da sociedade, a escolarização, tal qual a civilização, é um processo dado, terminado; é preciso cuidar de sua continuidade e de sua manutenção, e o problema remete-se aos números: verbas, vagas, salários, aprovações, repetência, avaliação, prédios, salas, computadores, livros etc.

É possível que isso não seja suficiente. É possível que tenhamos que refletir sobre os próprios princípios que possibilitaram a monopolização dos saberes pelo Estado e propor problemas de outra natureza. Podemos referir-nos, por exemplo, às configurações sociais que atravessam as práticas escolarizadoras e a dissonância manifesta aí presente como indicativo dos limites das formas de escolarização estabelecidas. É evidente que as tensões entre as formações sociais já não se configuram mais mediante determinados padrões de racionalidade, apesar da insistência da escola em ser o espaço de difusão de uma razão universal. Penso que precisaríamos esforçarmo-nos exatamente para contrariar a lógica racionalizadora dos processos de escolarização. 
Neste instante, tomo um novo rumo nas análises e vou dialogar com a literatura. O texto é muito conhecido: Seis propostas para o próximo milênio, de Italo Calvino (1993). O que nos encanta e seduz nesse texto é a maneira como o autor, referindo-se à crise contemporânea da linguagem, apresenta algumas qualidades que somente a literatura pode preservar. Mas são virtudes que norteiam não apenas a atividade dos escritores, mas cada um dos gestos de nossa existência: a leveza, a rapidez, a exatidão, a visibilidade, a multiplicidade e a consistência, sendo que esta última, pela morte súbita do autor, não foi desenvolvida.

As reflexões que trago para este momento, também em meio à crise contemporânea da educação, são somente parte de um esforço de pensá-la sob um outro prisma, ou melhor, contribuir para a produção de outras condições de possibilidade de educação.

A primeira virtude é a preservação da leveza, não associada a algo vago ou sutil, mas à precisão e à determinação. Numa época em que se advoga pela densidade, solidez, espessura, peso, precisamos por vezes deixar-nos sustentar pelas nuvens. Dos pesos maiores herdamos o controle, a autocoerção - não é exatamente esta a origem da escolarização? A sutileza pela qual os controles adentraram em nossos corpos e mentes tornou-se um peso insustentável em nossa cultura ocidental.

Associar leveza e educação seria produzir esforços precisos e determinados para escaparmos da petrificação de que nos tornamos reféns. A leveza do educador, por exemplo, consistiria em sobrelevar o peso do mundo, colocar em movimento o conhecimento, e principalmente a dúvida, fazer implodir aquilo que nos parece tão sólido e tão verdadeiro.

Apresentar a rapidez como uma qualidade a ser preservada pode parecer-nos espantoso. Entretanto, a reflexão aqui é com o intuito de pensar a maneira como o próprio tempo esteve representado na sociedade, fundamentalmente se impondo como velocidade física; mas, em contrapartida, ganhamos agilidade mental, o que nos tem possibilitado como nunca detectar diferenças. Nesse sentido, ao relacionar educação e rapi- dez estaríamos propondo um exercício de economia da velocidade física em razão da exploração da nossa agilidade mental e do cultivo do prazer; de, em curtas e em longas durações, aproximarmo-nos com maior refinamento das diversidades das ações humanas.

Outra virtude a ser preservada, como propõe Calvino, é a exatidão. Isso porque somente chegamos ao incerto, ao diferente, pelo olhar meticuloso. Cultivar a exatidão é o que nos possibilita a dúvida, elemento valioso para dialogarmos com o passado e com o presente. Quanto mais procuramos a exatidão, mais deparamo-nos com a incerteza; é o nosso olhar atento e detalhista que nos possibilita perceber as diferenças. Sem exatidão, corremos o risco de massificar e homogeneizar as nossas atitudes e a nossa compreensão do outro, não percebendo o universo múltiplo, tão presente nas relações de educar.

É difícil falar em educação sem associar a visibilidade, a quarta virtude proposta por Calvino. O visível forma-se mediante imagens que representam algo. A capacidade de elaborar imagens, de produzir pensamentos, refere-se à imaginação, ao sonho, à fantasia. Os processos escolarizados disseminaram a prática de produzir e transmitir modelos por intermédio de determinadas imagens que traduziram padrões de comportamento, valores e hábitos, sem dar-se conta de que há outra, aquela imaginada pelos alunos. $\mathrm{Na}$ prática unilateral dessa relação instalou-se a obscuridade. Portanto, preservar a visibilidade é não pôr em risco uma capacidade humana fundamental: a de imaginar, criar fantasias, transgredir - tornar visíveis os nossos sonhos.

Outro valor é a multiplicidade. É impossível pensar em nossas ações educativas sem darmo-nos conta da polifonia presente nos sujeitos, expressos nas diferentes vozes e olhares sobre o mundo, bem como da multiplicidade presente em tempos e espaços divergentes, convergentes e paralelos.

Calvino não desenvolveu a consistência, mas poderíamos atrever-nos a dizer, não em nome dele, evidentemente, que as relações entre educação e consistência bem que poderiam se estabelecer na tarefa de desconstruir os micropoderes por meio de argu- 
mentos e práticas que tornassem nossos anseios de solidariedade e respeito mais concretos.

Poderíamos pensar na construção de uma ação educativa que se fizesse em outras redes, nas quais fios diferenciados e múltiplos tecessem a trama do bordado, constituídos pela leveza, pelo exercício da agilidade na percepção dos desenhos, pelas dúvidas que nosso olhar meticuloso e exato pudesse proporcionar, pela visibilidade e imaginários possíveis de serem captados, e pela multiplicidade de olhares que um bordado dá a ver.

CYNTHIA GREIVE VEIGA, doutora em história pela Universidade Estadual de Campinas (UNICAMP), é professora adjunta de História da Educação na Faculdade de Educação da Universidade Federal de Minas Gerais (UFMG). Desenvolve atualmente programa de pós-doutoramento no Departamento de História da Universidade de São Paulo (USP). Publicou Infância no sótão em co-autoria com Luciano Mendes de Faria Filho (Belo Horizonte: Autêntica, 1999); Cidadania e educação na trama da cidade: a construção de Belo Horizonte em fins do século XIX (Bragança Paulista: Editora da Universidade de São Francisco, 2002), além de artigos e capítulos de livros. E-mail: greive@fae.ufmg.br

\section{Referências bibliográficas}

CALVINO, Italo, (1993). Seis propostas para o próximo milênio. São Paulo: Companhia das Letras.

CHARTIER, Roger, (1990). A história cultural, entre práticas e representações. Rio de Janeiro: Bertrand Brasil.

DUBY, Georges, (1998). Ano 1000, ano 2000: na pista de nossos medos. São Paulo: Fundação Editora da UNESP.
ELIAS, Norbert, (1980). Introdução à sociologia. Lisboa: Edições 70 .

, (1993). O processo civilizador: formação do estado e civilização. Rio de Janeiro: Zahar. v. 2.

, (1994a). O processo civilizador: uma história dos costumes. $2^{\text {a }}$ ed. Rio de Janeiro: Zahar. v. 1.

, (1994b). A sociedade dos indivíduos. Rio de Janei-

ro: Zahar.

FERREIRA, Antônio Gomes, (1988). Três propostas pedagógicas de finais de seiscentos: Gusmão, Fènelon e Locke. Coimbra: Imprensa de Coimbra.

FOUCAULT, Michel, (1972). A arqueologia do saber. Petrópolis: Vozes.

, (1978). História da loucura. São Paulo: Perspectiva.

(1988). História da sexualidade. Rio de Janeiro:

Graal. v. 1

, (1981). Microfísica do poder. $2^{\mathrm{a}}$ ed. Rio de Janeiro:

Graal.

, (1995). As palavras e as coisas. $7^{\mathrm{a}}$ ed. São Paulo:

Martins Fontes. , (1996). Vigiar e punir. 13ª ed. Petrópolis: Vozes.

GARRIGOU, Alain, LACROIX, Bernard, (orgs.) (2001). Norbert

Elias: a política e a história. São Paulo: Perspectiva.

NIETZSCHE, Friedrich, (1974). Obras incompletas. São Paulo: Abril (coleção Os Pensadores).

Recebido em agosto de 2002 Aprovado em outubro de 2002 
Ana Canen e Angela M. A. de Oliveira Multiculturalismo e currículo em ação: um estudo de caso

O multiculturalismo, campo teórico e político voltado para a valorização da pluralidade cultural e para o desafio à construção das diferenças, tem adquirido visibilidade crescente no campo educacional. Tendo em vista a incrementar a produção do conhecimento sobre possíveis formas de tradução do projeto multicultural para o currículo em ação, o presente estudo objetivou responder à seguinte questão central: o que seria uma prática pedagógica multicultural crítica? Para tal, analisa criticamente dados provenientes de um estudo de caso de cunho etnográfico, focalizando uma prática pedagógica identificada como portadora de "potenciais multiculturais". Sugere, a partir da confluência entre teoria e empiria, categorias centrais para o currículo em ação multiculturalmente comprometido.

Palavras-chave: multiculturalismo, currículo em ação, pluralidade cultural.

Multiculturalism and curriculum in action: a case study

Multiculturalism, a theoretical and political field aimed at valuing cultural diversity and challenging the construction of differences, has been gaining increasing visibility within the educational arena. Based on that approach, the present paper aims to contribute to the production of knowledge related to possible ways of translating the multicultural project into the curriculum in action. It seeks to answer the following central question: what is a critical multicultural pedagogical practice? In order to do so, it analyses data from an ethnographic case study that focused on a pedagogical practice informed by "multicultural potentials". From the articulation between theory and empirical evidence, the paper advances in the presentation of categories deemed crucial for a multiculturally oriented curriculum in action.

Key-words: multiculturalism, curriculum in action, cultural plurality.

Maria Onete Lopes Ferreira

A crise dos paradigmas e o marxismo entre os pesquisadores em trabalho $\mathrm{e}$ educação em universidades brasileiras

Tomando como problema a crise na qual mergulharam as teorias do conhecimento na atualidade, reflete sobre as conseqüências de tal momento de fragilidade teórica no campo da pesquisa educacional, especialmente entre os estudiosos que tratam de objetos referentes à relação "Trabalho e Educação". As fontes eleitas foram as teses produzidas nos Programas de Pós-Graduação em Educação das universidades PUC/SP, USP, UNICAMP, UFRJ e UFRGS, entre os anos de 1994 e 1998. O critério definidor do intervalo está amparado no fato de que, seguramente, a partir daquele momento inicial seria possível contemplar a problemática da crise dos referenciais, e que este intervalo deveria fechar-se no instante em que tivesse início o trabalho de campo. A questão norteadora da investigação teve como eixo o nível de compromisso dos pesquisadores com as teorias historicistas, em especial o marxismo, assim como com aquelas ditas pós-modernas. O resultado do trabalho demonstra ampla predominância do referencial marxista entre os pesquisadores investigados.

Palavras-chave: crise dos referenciais, marxismo, pós-moderno.

The crisis of paradigms and Marxism amongst educators Examines the consequences for educational research of the crisis in which the theories of knowledge are actually immersed. It especially examines research whose authors take as object of investigation themes concerning the relationship between work and education, since these themes are common objects of research in Post-graduate Programmes in Education in Brazil. Theses produced at PUC/SP, USP, UNICAMP, UFRJ and UFRGS, between 1994 and 1998, were examined. The period of research was determined by the year in which the crisis in social science investigation was first detected in Brazil, and the year in which this study was initiated. The aim of the investigation was to examine the nature of the research commitment to historical theories, especially Marxism, as well as to the so-called post-modern theories. The result of the investigation shows an ample predominance of Marxist theoretical frameworks among the researchers studied.

Key-words: crisis of theoretical frameworks, marxism, post-modern.

Solange Jobim e Souza e Nilton Gamba Jr.

\section{A escolarização como um projeto de} civilização

$\mathrm{O}$ artigo discute as contribuições de Michel Foucault e Norbert Elias para a historiografia da educação e para a história da escolarização. Especificamente, desenvolve, a partir de Norbert Elias, uma reflexão sobre o significado da monopolização do ensino elementar pelo Estado, no século XIX e nas sociedades ocidentais, enquanto estratégia fundamental para completar o projeto de civilização.

Palavras-chave: escolarização, civilização, Estado.

Schooling as a project of civilisation This paper focuses on the ideas of Michel Foucault and Norbert Elias and their ascendancy in the studies of the history of education and schooling. Based on Elias's studies, it has the purpose of analysing the relationship 
between the civilisation process and the monopolisation of the elementary school by the State.

Key-words: schooling, civilisation, state.

Cynthia Greive Veiga

Novos suportes, antigos temores: tecnologia e confronto de gerações nas práticas de leitura e escrita

Analisa as condições de produção de conhecimento na contemporaneidade e os condicionamentos sociais, políticos e culturais que levam às transformações do ato de ler e de escrever. A questão da leitura e da escrita é tratada sob dois aspectos: a interferência de suportes, que transforma os modos de leitura e da escrita através dos tempos; e os desafios trazidos pela revolução eletrônica para o diálogo entre as gerações. Conceitos desenvolvidos por Mikhail Bakhtin são retomados neste contexto para elaborar uma compreensão dos atuais usos da linguagem e criação de textos mediados por suportes eletrônicos e digitais.

Palavras-chave: tecnologia, práticas de leitura e escrita.

New supporting materials, old fears: the technology and the generation clashes in the reading and writing practices

The paper analyses contemporary production of knowledge about the act of reading and writing, as well as the social, political and cultural conditionings that have led to changes in it. We focus on two aspects related to the issue: the impact of the supporting materials that have changed ways of reading and writing throughout time; and the challenges imposed on the dialogue between generations, brought about by the electronic revolution. We revisit concepts developed by Mikhail Bakhtin, casting new lights upon the present uses of language and text production mediated by electronic and digital supporting materials.
Key-words: technology, reading and writing practices, supporting materials.

Maria de Lourdes de Albuquerque Fávero

\section{GT Política de Educação Superior} da ANPEd: origem, desenvolvimento e produção

O estudo objetiva oferecer subsídios para a compreensão da trajetória do GT Política de Educação Superior, situando suas origens, sua construção e desenvolvimento. Na história desse GT, destaca como os seminários de intercâmbio e, em especial, o projeto integrado de pesquisa "Produção científica sobre educação superior no Brasil: 1968-2000" contribuíram para seu caminhar, proporcionando avanços na reflexão coletiva sobre seu papel e questões de política de educação superior a ele afetas, bem como fortalecendo sua produção. Em uma visão prospectiva e tendo presente que o trabalho de consolidação de um grupo como este é empreendimento que resulta de um processo de construção permanente, indica questões a serem discutidas e aprofundadas pelos seus membros.

Palavras-chave: GT Política de Educação Superior.

Origins, development and production of the ANPEd Working Group on Higher Education Policy This study seeks to offer subsidies for understanding the trajectory of the Working Group on Higher Education Policy, situating its origins, construction and development. In the history of this working group, emphasis is given as to how the seminars of exchange and, specially, the integrated research project on "Scientific production on higher education in Brazil: 1968-2000" contributed to its advance in terms of the collective reflection it permitted on its role and questions of higher education policy, as well as strengthening its academic production. In a prospective vision and bearing in mind that the work of consolidation of a group like this is an undertaking resulting from a process of permanent construction, the article poses questions to be discussed and debated by its members.

Key-works: Working Group on Higher Education Policy.

Cecília Goulart e Sonia Kramer

Alfabetização, leitura, escrita: 25 anos da ANPEd e 100 anos de Drummond

A partir de revisão realizada com base em diversos textos: históricos, relatórios, livros de programação e de resumos de reuniões anuais da ANPEd, o artigo busca rever a trajetória do grupo de trabalho "Alfabetização, leitura e escrita", no período de 1991 a 2001. Destaca eixos temáticos e áreas de conhecimento trabalhadas, indica e analisa conquistas e fragilidades, mapeando a atuação do GT e revelando aspectos da história da própria Associação. O poeta

Drummond, no ano da comemoração de seus 100 anos, percorreu conosco o período, revelando a realidade estudada para além do visível, ressaltando a simplicidade como critério. $\mathrm{O}$ texto é dedicado à professora Magda Soares, uma das fundadoras do GT, com relevante e marcante produção na área de estudo.

Palavras-chave: alfabetização, leitura e escrita, grupo de trabalho.

Literacy, reading and writing 25 years of ANPEd and 100 years of Drummond

This article seeks to review the trajectory of the working group "Literacy, reading and writing", in the period 1991-2001, based on an analysis of diverse historical texts, reports, programmes and abstracts of the annual meetings of ANPEd. It 